\title{
Minimally Invasive Endodontics and Endo-endorestorative- Prosthodontic Continuum: The Right Balance?
}

\author{
Sekar Mahalaxmi
}

\begin{abstract}
The ultimate goal of any operative procedure is to restore the tooth to its original form and function within the arch as well as to reestablish esthetics wherever applicable. The primary objective of the endodontic therapy is the elimination of bacteria and their by-products, pulpal remnants, and debris from the root canal system. To achieve this goal, the biomechanical aspects of the tooth structure are often compromised, leading to the questionable prognosis of the restorative factor of endodontically treated teeth (ETT). The current technological advancements in the field of endodontics that preserves more natural tooth structure and adhesive dentistry that enables better restoration of the lost tooth structure, when used in the optimal way, can pave a path for the right balance between the endodontic and restorative components of teeth. This narrative review highlights the ways in which the right balance can be achieved between the two.

Keywords: Dentin biomechanics, Endodontics and endo-endorestorative-prosthodontic, Ferrule effect, Minimal invasive endodontics, Post endodontic restoration, Vertical root fracture.
\end{abstract}

Journal of Operative Dentistry and Endodontics (2019): 10.5005/jp-journals-10047-0075

\section{INTRODUCTION}

It is always better to start with the end in mind...

The primary goal of the endodontic therapy is to render the root canal system completely free of bacteria and its toxins, tissue remnants, and debris and to biologically seal the entire system to prevent reinfection. To achieve this objective, various procedures and materials are used that subsequently have a deleterious effect on the structural integrity of the tooth (Fig. 1). On the other hand, the primary objective of any restorative procedure is to restore the tooth to its original form, function, and esthetics that can survive for a reasonably long period of life. This can be achieved only by retaining as much natural tissue as possible without affecting their biomechanical properties. Hence, the ultimate goal of the endodontic treatment should thereby be not only to achieve the biologic objectives mentioned above but also to leave behind a restoratively viable tooth structure that when restored can withstand the forces of mastication and function for a very long time ${ }^{1}$ (Fig. 2).

\section{Failure of Endodontically Treated Teeth}

Though endodontic treatment is a predictable procedure with more than $95 \%$ success rate, ${ }^{2}$ the failure of ETT due to nonmicrobial and biological factors remains a bone of contention for the clinician. Aggressive endodontic treatment procedures, be it extensive cavity preparations, wide tapered coronal and apical instrumentations, or aggressive obturation techniques, may result in irreparable vertical root fracture (VRF) that is catastrophic (Fig. 3). The remaining tooth structure is the key factor determining longterm prognosis of ETT. ${ }^{3}$ Coronal tooth structure loss may be due to caries, trauma, or access cavity preparation, while radicular dentin is lost due to pathological resorption and during shaping and cleaning of the root canals. ${ }^{4}$ The reasons for the extraction of ETT are manifold, the major reasons as stated by Touré et al. being periodontal diseases $(40.3 \%)$, followed by endodontic failure (19.3\%), nonrestorable crown fractures (15.1\%), VRF (13.4\%), and others (10.2\%). ${ }^{5}$ The most commonly extracted tooth is the mandibular molar without cuspal coverage (94\%). ${ }^{5}$ The failure of
Department of Conservative Dentistry and Endodontics, SRM Dental College, Ramapuram, Chennai, Tamil Nadu, India

Corresponding Author: Sekar Mahalaxmi, Department of Conservative Dentistry and Endodontics, SRM Dental College, Ramapuram, Chennai, Tamil Nadu, India, e-mail: researchmaha@gmail.com

How to cite this article: Mahalaxmi S. Minimally Invasive Endodontics and Endo-endorestorative-Prosthodontic Continuum: The Right Balance? J Oper Dent Endod 2019;4(1):42-53.

Source of support: Nil

Conflict of interest: None

ETT under function resulting in fracture (that cannot be restored) is the outcome of two opposing etiological factors. These include the inherent biomechanical properties of the remaining dentin that contributes to the fracture resistance as against the degree of stress endured by the weakened tooth structure under occlusal load, which makes it prone to fracture. ${ }^{3}$

PradeepKumar et al. studied the factors predisposing to VRF in ETT and found that elderly individuals, females, posterior teeth, overfilled teeth, and teeth with crowns are more prone to VRF. ${ }^{6}$ Non-ETT may also fracture, predominantly in elderly males with heavy masticatory forces and/or preexisting tooth structure loss due to parafunctional habits.,

With more and more people of the older age group seeking to retain their teeth, long-term retention of such endodontically treated compromised tooth structure becomes a daunting task. This compromise may be age related, physiologic and pathologic changes in the dentin, previous restorative procedures performed, tissue damage due to oral conditions over time, etc.

Kishen proposed the mechanisms of fracture resistance of dentin and the fracture predilection of ETT. ${ }^{4}$ It is important to understand the biomechanics of dentin to enable better handling of the tissue to achieve an ideal prognosis.

Generally, the tooth type, root dentin thickness, root canal diameter and cross-sectional shape and taper of the root canal 

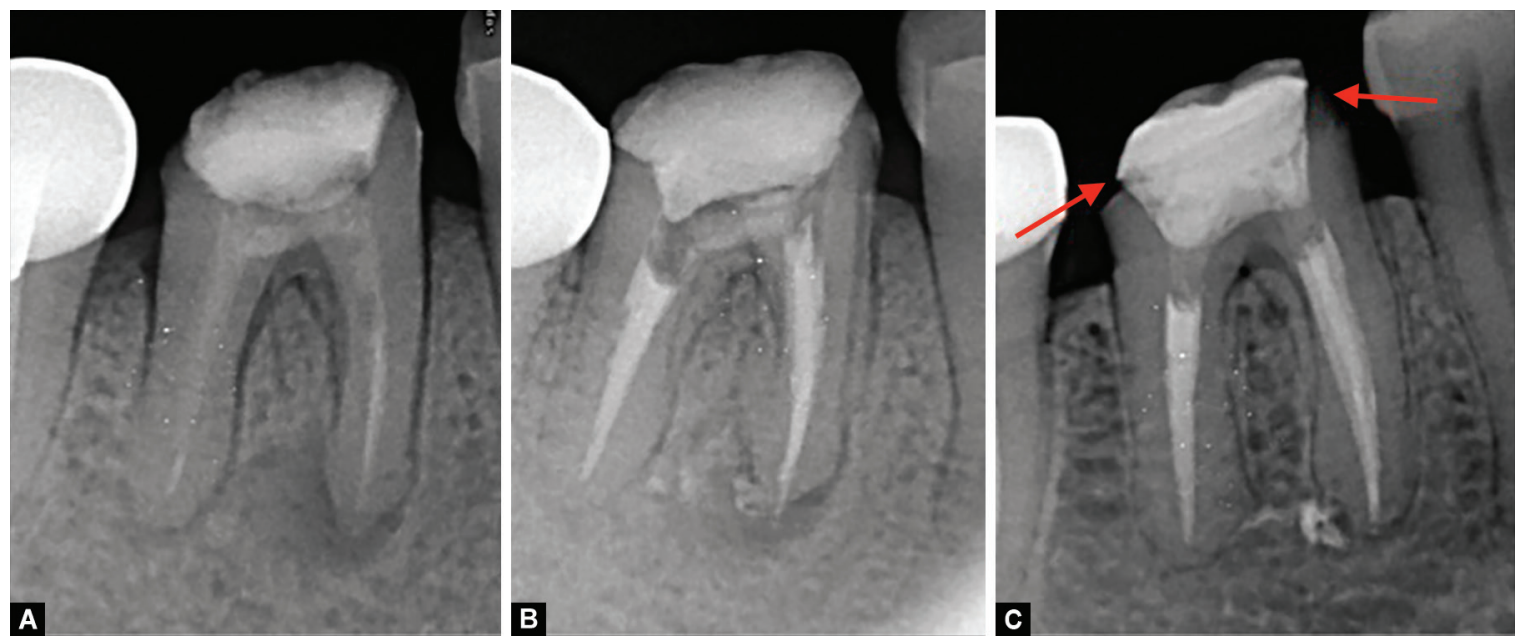

Figs $1 \mathrm{~A}$ to $\mathrm{C}$ : Successful endodontic treatment with doubtful restorative prognosis in ETT. (A) Retreatment of a mandibular molar with previous crown and a large periapical lesion attempted. Intracanal placement of $\mathrm{CaOH}$; (B) Immediate post-obturation radiograph. Note the aggressive coronal preparation; (C) 2-year follow-up radiograph shows adequate healing of the periapical lesion. However, an inadequate coronal tooth structure with lack of ferrule (red arrows) resulting in loss of crown



Fig. 2: Restoratively viable ETT. Courtesy: Dr Leeba Varghese, MDS, Kottayam, Kerala instruments used, preparation methods, size of the apical preparation, and post space preparation have an influence on the fracture resistance of ETT. ${ }^{1}$ The thinner the root dentin, the greater is the risk of fracture; circular canals show lower and more uniform stress distribution than oval canals. ${ }^{9}$

\section{Biomechanics of Dentin}

The study of a biological structure and its function using principles of engineering mechanics is known as biomechanics. ${ }^{10}$ The viscoelastic behavior of dentin can be attributed to its water content, where the organic collagen provides toughness and the inorganic portion is responsible for the stiffness and ultimate compressive strength of dentin. ${ }^{4}$ Dentin is stronger in compression than in tension. The water present in the dentin along with the confined pulpal environment and the fluid within the dentinal tubules helps in absorption and distribution of the stresses, preventing fracture of dentin.'

The biomechanical behavior of dentin can be altered at three levels due to endodontic treatment, namely, tissue composition, dentin macro- and microstructure, and overall tooth structure. ${ }^{11}$
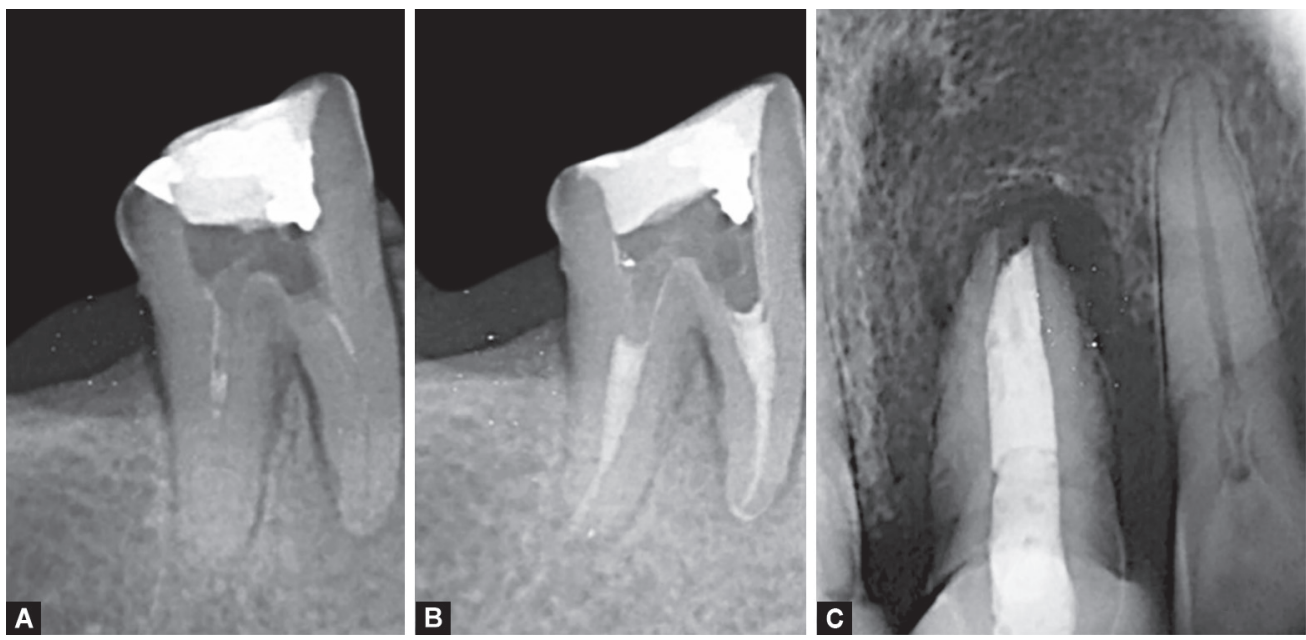

Figs 3A to C: Retreatment of (A) a mandibular molar with aggressive removal of (B) radicular dentin in the coronal third of the root, that may predispose to VRF; (C) Maxillary central incisor with VRF caused due to aggressive preparation with weakened tooth structure 
Major changes in tooth biomechanics are due to loss of the tooth structure as a result of caries, cavity preparation, including access cavities in ETT. ${ }^{11,12}$ The effect of coronal preparation is discussed in detail later in the article. It is also found that after endodontic treatment only up to $9 \%$ of predominantly free water content is lost, while bound water remains intact. ${ }^{11}$ However, a study done by Papa et al. showed no difference in the moisture content of both the teeth. ${ }^{13}$ No difference in the collagen cross-linkage or chemical alterations due to loss of the pulpal tissue was reported. ${ }^{11}$

Though the loss of the moisture content is said to be about only $6-9 \%$, this may not translate to the clinical scenario as most of these studies have been done on intact but extracted teeth, without intact pulpal tissue and the associated intrapulpal pressure. An intact tooth consists of vital pulp with more than $90 \%$ water content and an intrapulpal pressure of $10-28 \mathrm{~mm} \mathrm{Hg}$ that results in an outward flow of the fluid into the dentinal tubules. ${ }^{14}$ The loss of this water-rich pulp tissue from the root canal space and the free water from the dentinal tubules when the root canal is dried and dehydrated before obturation may affect the mechanical properties of dentin. ${ }^{4}$

As age progresses, due to physiological and pathological processes, more and more minerals are deposited replacing the water and increasing the brittleness of dentin, resulting in reduced mechanical properties. ${ }^{15}$ Fracture toughness of transparent dentin is $20 \%$ lower, one of the reasons being loss of the water content. ${ }^{4}$ Though the number of mineral-filled tubules increases all along the entire length of the root with age, the occlusion ratio and the mineral-collagen ratio were primarily found more in the apical and middle thirds of the root. ${ }^{15}$ Moreover, sclerosis begins in the mesial and distal quarters of the root dentin and then progresses to the buccal and lingual aspects creating a "butterfly effect," again more pronounced in the apical and middle thirds of the root. ${ }^{15}$ Similarly, microcracks were found to be present in higher percentage in non-ETT of elderly patients (8.3\%) as compared to younger teeth $(3.7 \%)$, more in the mesiodistal direction. ${ }^{16}$ Whether there is a correlation between the "butterfly effect" and the microcracks and their effect on VRF is not clear. Russell et al. showed that tubule density was lower in the mesiodistal directions compared to the buccolingual, while microhardness was higher in the mesiodistal directions. ${ }^{17,18}$ This may explain the prevalence of VRF in the buccolingual direction.

The flexural strength of coronal dentin reduces from about $150 \mathrm{MPa}$ to $80 \mathrm{MPa}^{19}$ with an approximate reduction of $25 \mathrm{MPa}$ per decade. The average reduction of total strength is about $40 \%$, while the endurance limit is reduced by $30 \% .{ }^{15}$ This deterioration is accentuated in $\mathrm{ETT}^{20}$

An optimum balance between stiffness (mineralization) and dynamic toughness (collagen and water of hydration) is crucial for the structural stability of dentin. ${ }^{21}$

With enhanced vision and illumination, the success rate of endodontic treatment is steadily increasing. Within this framework, if preservation of sound coronal and radicular dentin is included, along with application of adhesive concepts, it will bridge the gap between traditional aggressive endodontics and extensive prosthodontics management. ${ }^{22}$ This encompasses the concept of minimal invasive dentistry in the endodontic procedure.

\section{Minimal Invasive Endodontics}

Minimal invasive endodontics (MIE) is the term used to denote endodontic procedures done with as minimal intervention as possible with maximal protection of the natural tooth structure. Minimal invasive endodontics involves judicial care of three areasaccess cavity, apical preparation, and cervical area (pericervical dentin) of the tooth. ${ }^{23}$

Straight-line access to the apical region is one of the principles of old-school endodontics. Previously, the access cavity was prepared with an occlusal flare to accommodate the inflexible hand stainless steel instruments and the greater taper NiTi rotary instruments. ${ }^{3}$ The principle of modern conservative endodontic access cavity is to remove as little tooth structure as is necessary, without compromising the mechanical objectives of cleaning and shaping ( $\mathrm{C}$ and $\mathrm{S}){ }^{23}$ Endodontic access conducted through extremely small openings (ninja access) may result in not only improper $\mathrm{C}$ and $\mathrm{S}$ but also underfilled root canal system. ${ }^{21}$ Studies show that ultraconservative ninja access results in missed canals, incomplete removal of the pulp tissue with no significant increase in the fracture resistance of these teeth. ${ }^{24}$ With the routine use of magnification for endodontics, access need not necessarily mean straight-line visibility of all the canal orifices.

Root canal instrumentation will cause dentinal defects in the root dentin that undergoes mechanical cycling subsequently during obturation and later during function as well. ${ }^{18}$ Maximum risk of root fracture is found with over-instrumentation with resultant excessive removal of radicular dentin, especially in noncircular, oval canals with thin roots. ' Flexibility of each root canal instrument decreases with increasing the core diameter, regardless of its design and alloy composition/type of alloy. Consequently, straightening tendency is more pronounced when enlarging severely curved canals to a greater apical preparation size. ${ }^{25}$ Modifications in the metallurgy of the NiTi alloy ( $\mathrm{M}$ wire, Controlled Memory, ECM) resulting in more flexible rotary and reciprocating instruments are shown to preserve the root canal curvatures better. ${ }^{25}$ However, both rotary and reciprocating technics produce microcracks in the radicular dentin that may predispose to VRF. ${ }^{25}$ Apart from these motions, other instrument kinematics including self adjusting files (SAF), XP endo shaper and finisher, and TRUShape 3D have been introduced that are supposed to be less invasive, and better in preserving root dentin, at the same time well effective in cleaning the irregular and inaccessible canal intricacies. ${ }^{26-29}$

Other factors affecting the fracture resistance and fracture patterns are curvature of the external root surface, canal size and shape, and dentin thickness. ${ }^{30}$ Chatvanitkul and Lertchirakarn showed that increase in curvature of the external root surface resulted in increase in volume and area of stress concentration in root dentin. ${ }^{30}$

Reduced taper of instruments results in lesser dentin removal; favoring $4 \%$ taper NiTi files over greater taper, with $2 \%$ hand instruments producing significantly lesser microcracks compared to rotary files. ${ }^{31}$

The modulus of elasticity (MOE) and flexural strength of dentin may be influenced by the irrigants and intracanal medicaments used during $C$ and $S$; these products interact with the mineral and organic contents of dentin. The most commonly used irrigant is sodium hypochlorite $(\mathrm{NaOCl})$ in various concentrations. ${ }^{11}$ The tissue-dissolving and antibacterial effect of $\mathrm{NaOCl}$ is concentration and time dependent. However, prolonged exposure to higher 
concentrations of $\mathrm{NaOCl}$ has deleterious effects on the root dentin. ${ }^{32,33}$ Ethylene diamine tetraacetic acid (EDTA-17\%) used as a final irrigant removes the smear layer formed during the root canal instrumentation. Both $\mathrm{NaOCl}$ and EDTA remove the organic and inorganic content of dentin, respectively, resulting in undesirable effects on properties such as flexural strength, MOE, and microhardness. ${ }^{11}$ Some disinfectants, on the other hand, are known to increase the tensile strength of dentin via protein coagulation (formocresol) and chelation (eugenol) with hydroxyapatite. ${ }^{34}$

Obturation forces of lateral and vertical compaction may cause craze lines in the dentin that may predispose to VRF, especially in larger tapered preparations. Techniques that deliver obturating materials with minimal application forces and thoroughly fill the canals without necessitating wider preparations is essential to reduce its effect on the mechanical properties of root dentin. ${ }^{22}$

With enhanced vision and target-specific equipments, a more precise and conservative access cavity with minimal intervention, an enhanced irrigation protocol using various advanced irrigating systems, and use of biomaterials for root canal obturation, preservation of more natural dentin becomes possible, thus improving the survival rate of ETT (Fig. 4).

\section{Influence of Cavity Preparation on Tooth Stiffness}

Though it is understood that access cavity preparation reduces stiffness of the teeth to some extent, occlusal cavity designs are known to significantly affect the tooth flexure at the cementoenamel junction (CEJ). A study done by González-López et al. evaluated the influence of increasing dimensions of cavity designs, including access cavities, on cuspal deflection. ${ }^{12}$ Moreover, they evaluated these responses at increasing occlusal loads as well. They found that there was a significant increase in the cuspal deflections as the dimensions of the cavity increased. ${ }^{35}$ This deflection was also proportional to the load applied. ${ }^{12}$ They further noted that removal of both the marginal ridges along with an endodontic access resulted in a fivefold increase in the cuspal deflection under normal occlusal load to a tenfold increase when the load doubled. ${ }^{12}$ A conservative access cavity with a class I configuration reduces stiffness by about $5 \%$ only. ${ }^{11}$ The largest reduction in stiffness is with occluso-proximal cavities, especially those involving both the marginal ridges. Apart from this, depth of the cavity, width of the isthmus, and configuration are highly critical factors in determining tooth stiffness and resistance to fracture. ${ }^{36-38}$ Loss of anatomical structures and the resultant cuspal deflection, along with loss of protective feedback mechanism of vital teeth in an ETT, contribute to their increased susceptibility to fracture. ${ }^{39,40}$ The order of increased tooth deformation in ETT starts with intact teeth followed by access cavity preparation, after endodontic treatment and after post space preparation, with the latter showing the maximum deflection. ${ }^{41}$

The current trend of MIE-driven conservative access cavity preparation avoiding straight-line access to all canal orifices, at the same time, using the flexibility of the glide path files and the rotary instruments used, without compromising on the biological aspects of cleaning and shaping, can result in an adequately restored ETT that can survive for a long period of time in the oral cavity. The advocates of the so-called "ninja" and "truss" accesses suggest that coronal dentin preservation is of prime importance; however, its justification has still not been proven and studies have shown that
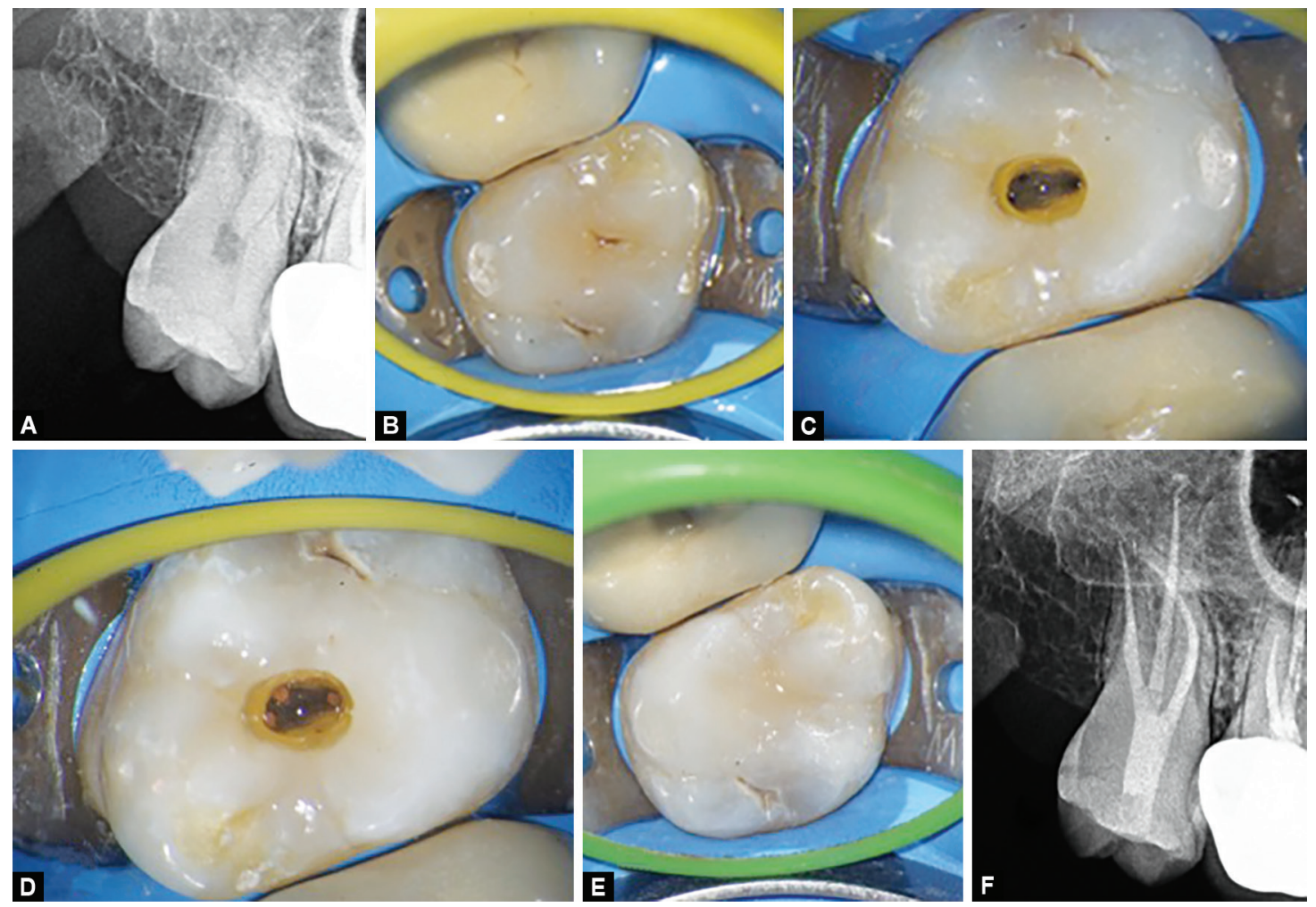

Figs 4A to F: Minimal invasive endodontics with bonded PER. (A and B) Preoperative radiograph and picture of an intact mandibular second molar with symptomatic irreversible pulpitis; (C and D) Ultraconservative access cavity prepared, narrow root canal preparations, and obturation; (E and F) Post-endodontic bonded direct composite restoration showing maximum preservation of the natural tooth structure. Courtesy: Dr Jojo Kottoor, MDS, Reader, Royal Dental College, Palakkad, Kerala, India 
this is achieved at the expense of incomplete removal of the roof of the pulp chamber, thereby reducing its visibility and removal of pulpal remnants. ${ }^{42}$ On the contrary, Clark and Khademi's directed dentin conservation (DDC) concept with contracted access design and soffit preservation has been accepted by many to be beneficial to the long-term prognosis of the ETT. ${ }^{43}$

\section{Post-endodontic Restorations (PERs)}

The best restorative option for a given clinical situation has always been controversial, even with the plethora of materials and techniques available. ${ }^{11}$ The selection of the restorative techniques including the choice of material for the ETT to be restored should be considered after evaluating many factors, which have been enumerated by the AAE guidelines ${ }^{44}$ as follows:

- Amount of remaining tooth structure

- Length, width, and curvature of the roots

- Occlusal function

- Opposing dentition

- Position of tooth in the arch.

Peroz et al. categorized remaining tooth structure into five classes based on the number of remaining walls from class I with all four walls remaining through to class V, the decoronated tooth with no remaining wall. This may be used for determining the type of PER to be placed. ${ }^{45}$ However, the information provided in this classification is inadequate, as it does not consider the thickness of the residual dentin on the walls, which is also important. Zarow et al. proposed a new classification system for restoration of ETT based on the restorative options available and considering many other factors. ${ }^{46}$ Most of the clinical studies fail to provide meaningful information about the biomechanical status of the ETT, hence the indication and performance of many materials and techniques

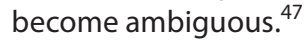

Most of the studies done with PERs revolve around the need for post and their influence on the fracture resistance of the restoration and the tooth. The core materials, if adhesive in nature, may not necessitate post placement or cuspal coverage, provided adequate tooth structure is available for bonding. When performing metallic restorations such as silver amalgam or gold alloys, cuspal coverage may become mandatory for long-term sustenance. ${ }^{11}$ Extensive access cavities involving one or more marginal ridges, when restored with amalgam or composite resin, tend to fracture over a period of time, if cuspal coverage is not done. ${ }^{1}$

The newer classification takes into consideration the amount of remaining radicular and coronal tooth structure, the function of the tooth in the arch; and the restorative options range from the composite core build up to fiber posts to cast gold posts to prerestorative extrusion procedures. ${ }^{46}$ However, the type of PER cannot be decided based only on the available tooth structure but is also based on the understanding of the effects of occlusion on the endo-restorative continuum.

\section{Endo-endorestorative-Prosthodontic CONTINUUM AND OCCLUSION}

The effect of occlusal forces and stresses cannot be ignored, as the teeth have to survive in a dynamic oral environment. During mastication, the teeth will be under stress due to the occlusal forces acting on them. The distribution of these stresses depends upon the direction of load applied, the shape of the tooth involved, and the angle at which it is incident on the surface of the tooth. ${ }^{4}$ Loss of pulp and continuity with the periodontal ligament results in reduced proprioception of the tooth, which can lead to uncontrolled occlusal forces. ${ }^{46}$ The long-term success of the PER depends on the ability of the restorative material and the tooth structure, along with the interface between the two, to withstand and function under these stresses.

Forces acting on anterior teeth are different than those acting on molars. ${ }^{43}$ Though premolars are subjected to major compressive components during function, they also undergo a shear stress at the extremely delicate cervical area of the tooth. While molars are subjected to predominantly larger compressive forces, the anteriors undergo more shear stresses directed at the cervical area, with compressive occlusal forces being negligible. ${ }^{43}$

Maxillary anterior teeth are subjected to milder and more oblique shear stresses, hence the neck of the tooth should be of primary concern. Though molars undergo heavier occlusal forces, most of them are vertical and compressive in nature; hence, a post is not necessary even if there is extensive loss of the coronal tooth structure, provided a ferrule of at least $1 \mathrm{~mm}$ is present all around. ${ }^{43}$ Hence, PERs cannot be generalized based on the amount of remaining tooth structure alone.

The intensity of stresses and stress concentrations increase significantly when the load applied is not along the long axis of the tooth. This is more pronounced in post-retained ETT, due to increased stiffness of the post and angulation of the post in relation to the direction of the force, along with increased flexure of the remaining tooth structure. ${ }^{4}$

Generally molars can withstand high compressive stresses, since they act along the long axis of the tooth. The buccal cusps of lower molars and the palatal cusps of the upper molars take up most of the compressive loading. Their opposing cusps are subjected to tensile stresses along their cuspal inclines that may lead to their fracture if there is a prolonged breach in the intercuspal region (Fig. 5).

Keeping all the factors in mind, the occlusal design is planned so as to reduce the magnitude of stresses by providing occlusal points of contact not wider surface of contact with the opposing teeth. ${ }^{47}$ Possible occlusal interferences should also be identified and adjusted. ${ }^{46}$

\section{Ferrule and Ferrule Effect}

There are two ways of defining a ferrule. It is a $360^{\circ}$ encircling band of metal that embraces the circumference of the tooth structure around the cervical area. ${ }^{4}$ This ferrule is given on the fabricated core/ crown (and named as core ferrule or crown ferrule, respectively) so as to reinforce the remaining tooth structure during PER. However, the same ferrule needs to be achieved in the tooth itself, which then can be defined as a circumferential area of axial dentin coronal to the preparation margin or cervical area of the tooth. ${ }^{45}$

The ferrule effect is the protective effect that results from the presence of a ferrule that resists stresses caused by the wedging effect of the posts and the functional lever forces that act during masticatory load. ${ }^{48}$ Without this ferrule, ETT cannot be considered restorable and the best option would be extraction followed by an implant. To add further to this, the traditional ferrule is not the only determining factor for the long-term stability of the tooth. Hence it is more apt to use the concept of the three-dimensional (3D) ferrule. 

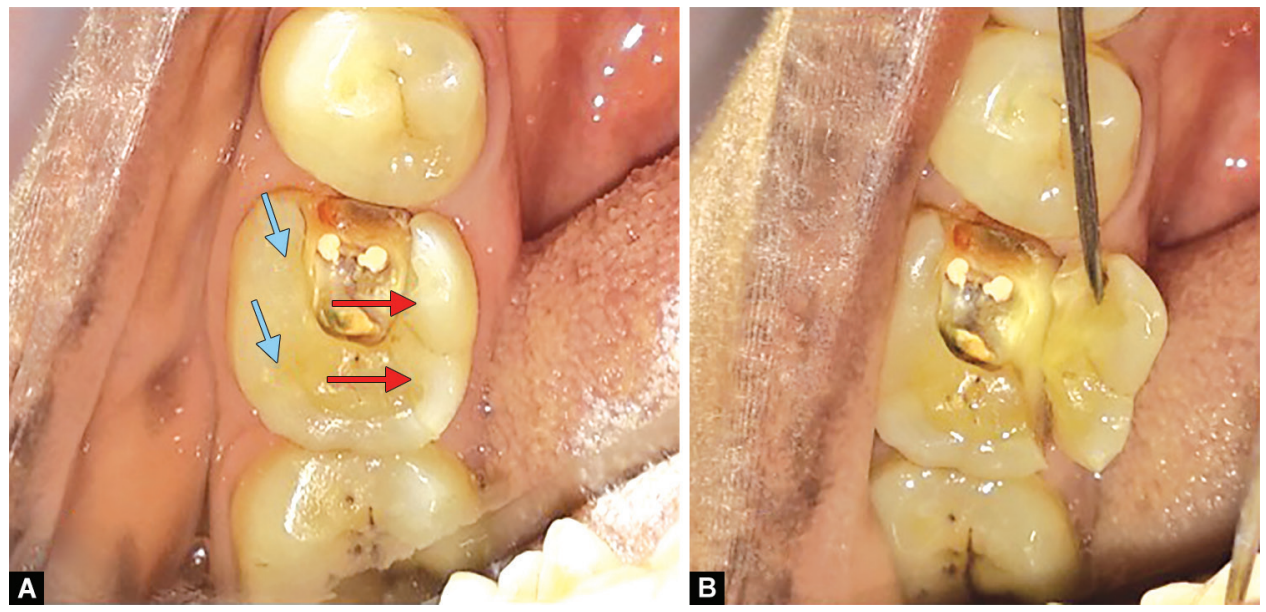

Figs 5A and B:Weakened cusps in ETT. (A) Buccal cusps of mandibular molars are subjected to predominantly compressive stresses (blue arrows), while shear stresses are directed toward the lingual cusps (red arrows) that may result in (B) their fracture if the tooth is left unrestored. Courtesy: Dr Anand, MDS, III year, SRM Dental College, Ramapuram, Chennai, Tamil Nadu, India

\section{D Ferrule}

The 3D ferrule is the backbone of prosthodontics reconstruction, the single most essential component for the reinforcement of the ETT, that can be defined as the axial wall dentin that encircles the cervical area of the tooth and that is covered by the axial wall of the crown. It differs slightly from the traditional ferrule in that it includes three components: traditional ferrule, dentin girth, and total occlusal convergence. ${ }^{49}$

The minimum axial height that is required ranges between 1.5 and $2.5 \mathrm{~mm}$ of the tooth structure (traditional ferrule). This does not take into account any restorative material used to achieve this ferrule. ${ }^{43}$ The second important component is the thickness of remaining dentin (dentin girth), mainly at the level of the CE junction. The dentin thickness between the finish line on the external tooth surface and the inner wall of the endodontic access cavity gains importance, more so as the finish line moves apically, since the tooth circumference reduces further apically. The third component of the 3D ferrule is the net taper (total occlusal convergence) of the external tooth preparation, which is the near parallelism of the opposing axial walls. ${ }^{43}$

Achieving a 3D ferrule may be a challenge in ETT; part of the ferrule may be derived from the core material. If not, then a partial ferrule is better than no ferrule at all. ${ }^{50}$

\section{Pericervical Dentin (PCD)}

The area of dentin at the plane of the alveolar crest region $(4 \mathrm{~mm}$ above and below) is considered critical for the long-term survival of ETT. The fracture resistance and the prognosis of ETT is directly related to the amount of $P C D$ present. ${ }^{43}$ Huynh et al. evaluated the effect of adhesive bonding on the PCD and showed that though the bonded PCD had favorable results under physiological load levels, with micro-strain distribution away from the apical region, under cyclic loading there was no significant difference with unbonded specimens. ${ }^{10}$ The orifice-directed DDC concept is directed at preserving this PCD to the maximum. ${ }^{43}$

\section{Posts and Core Materials}

Factors such as restorative materials used, cuspal coverage and direct/indirect procedure affect the performance of PERs over time. ${ }^{29}$ There are two methods for PERs: direct and indirect restorations. ${ }^{51}$ With either of the methods, use of a post is warranted when retention of the core is needed. Earlier treatment protocols included cuspal coverage; more specifically, crowns were part of the PER. Crowns act as an extracoronal "brace" that encircles the entire cervical part of the tooth and prevents shattering of the root due to its hugging action. ${ }^{48}$ However, with advances in adhesive technology and materials that can be further reinforced to improve their mechanical properties, direct composite resins have been used routinely without posts, when adequate ferrule is present all around the circumference of the tooth. Ideally, the core material should possess the following properties: improved compressive strength to resist intraoral forces of mastication, ${ }^{52}$ CTE similar to that of dentin, ${ }^{53}$ the ability to bond to the remaining tooth structure, ${ }^{54-56}$ minimal water sorption, ${ }^{57}$ and inhibition of dental caries. ${ }^{58}$ Glass ionomer cement is generally not used as a core material for this purpose, except in very conservative access cavities with intact occlusal surfaces and as a base for covering the root canal orifices during preparation of the tooth for inlays, onlays, and endocrowns. ${ }^{59}$ Here it is advantageous to use glass ionomer cement (GIC) due to its chemical adhesion and anticariogenic property.

Though the use of composite resins for PERs has been routinely accepted, they are still not used in extensive restorations, especially in high stress-bearing areas, ${ }^{60}$ as they have been shown to possess poor fracture resistance in all cavity designs. ${ }^{61}$ This is due to the poor adhesive interface and bond strength, which is the lowest at the pulpal floor, followed by radicular dentin and the chamber wall. ${ }^{62}$ In such situations, composite resins reinforced with particulate ceramic fillers, whiskers, and short fibers that improve their mechanical properties have been routinely found to be effective in reinforcing ETT. ${ }^{63-66}$ Eapen et al. proved that when both the marginal ridges are involved, chamber reinforcement with the short fiber composite (SFC) not only improves fracture resistance but all the fractures associated with SFC restorations were only in the enamel or dentin coronal to the cervical region of the tooth, favoring repair ${ }^{67}$ (Fig. 6). Further, using bulk fill composites such as a flowable composite as a base over the root canal orifices creates lower stresses in the ETT. ${ }^{68}$ Direct bonded restorations recover tooth stiffness by up to $88 \%$ of that of an unaltered tooth. ${ }^{69}$

To summarize, commonly used core materials are cast gold, silver amalgam, composite resins, and reinforced glass ionomer. 


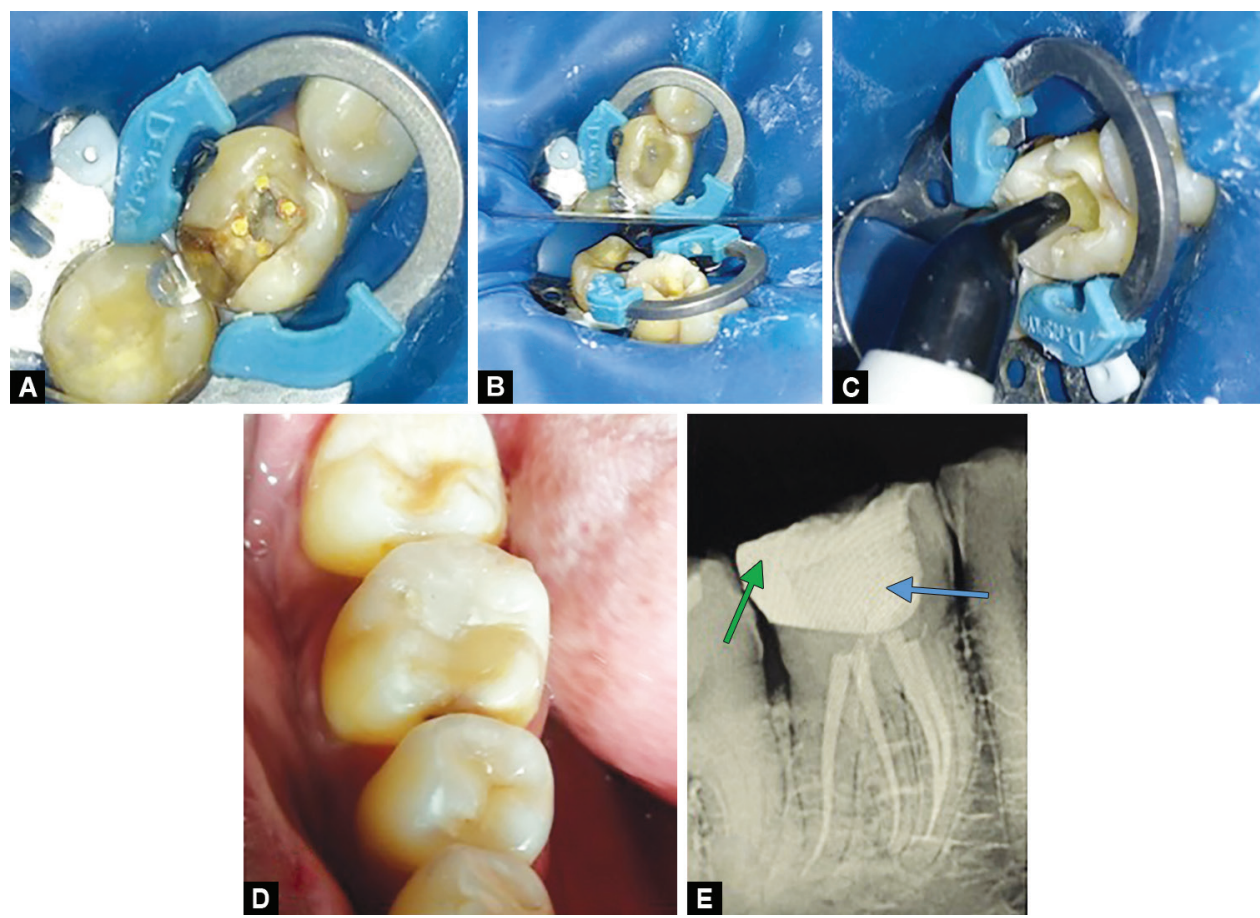

Figs $6 \mathrm{~A}$ to E: Post-endodontic bonded restoration with the reinforced composite resin. (A) Mandibular first molar with one wall missing, after application of the proper matrix system; (B) A thin layer of flowable composite to seal the canal orifices followed by building the proximal wall with the nanohybrid composite resin; (C) restoring the bulk of the cavity with the short-fiber composite resin (EverX Posterior, GC India) followed by $(D)$ a 2 mm cover with the nanohybrid composite resin; (E) Radiograph depicting both the materials due to a slight difference in translucency: short-fiber (blue arrow) and nanohybrid (green arrow) composite resins. Courtesy: Dr Anand, MDS III year, SRM Dental College, Ramapuram, Chennai, Tamil Nadu, India

But indirect cast gold requires multiple visits with castings to be done, while amalgam is in its phase-out stage. Reinforced GIC is still shown to be inferior to conventional composite resins in large cavity designs. Hence, it is advisable to use a reinforcing fiber/SFC when using a conventional composite resin alone as a core restoration. ${ }^{70}$

Sometimes it is imperative to restore the tooth prior to the start of the endodontic procedure when one or both marginal ridges/proximal surfaces are completely denuded due to caries, especially when the tooth carries higher risk of cuspal deflection and consequent irreparable fracture (Fig. 7).

In some clinical situations, it is necessary to perform indirect metallic or nonmetallic bonded intracoronal and/or full coverage restorations, especially when proper proximal contours and contacts need to be established, the entire occlusal surface has to be reproduced, loss of functional cusps of posteriors and the palatal wall of anterior teeth, etc. In the present context of minimal invasive dentistry (MID), wherever possible, intracoronal retention in the form of inlays with cusp coverage or onlays and endocrowns ${ }^{71}$ are preferred for restoration of ETT as compared to the use of two different materials in the form of a core and crown. These intracoronal restorations preserve the dentin girth and provide the ferrule effect in a more effective way (Fig. 8).

With regards to the use of posts, a meta-analysis of fracture resistance of cast posts versus fiber posts showed that cast posts had significantly higher resistance to fracture than fiber posts. ${ }^{72}$ However, fractures that occurred with cast posts were catastrophic in nature, with oblique or horizontal fractures in the middle third of the roots or VRF, while those of fiber posts were repairable with either fractures of the core or in the cervical thirds of the root. ${ }^{1,31}$
Similar fate as metal posts is also observed with zirconia or titanium posts due to the rigidity of the posts. ${ }^{11}$

The possible reason for favorable fracture and fracture resistance with FRC posts is their similar MOE to that of dentin that dissipates stress effectively. Since it is a prefabricated post, the space between such posts and the root canal wall is wider, and this space gets filled with the resin cement that is used to lute the post. This thick cement layer may act as a stress absorber under occlusal loading, thereby dissipating the forces and transmitting lesser stresses onto the roots. ${ }^{72}$ This is further reiterated by two studies done by Kathuria et al. and Ambica et al., ${ }^{73,74}$ in which they have used human dentin milled and shaped to the form of a post (1.5 mm diameter and $17 \mathrm{~mm}$ length) and showed better fracture resistance compared to FRC posts. Uniform stress distribution and shock-absorbing potential of dentin posts seem to be better as they form a biomechanically homogenous unit with the root dentin, suggesting that posts with similar physical properties as the remaining root dentin show the best results. ${ }^{73,74}$ This may be applied to the monoblock concept as well.

\section{Monoblock Concept}

For a monoblock to function effectively as one unit, the materials that make up the monoblock should bond to the substrate strongly. ${ }^{75}$ One probable example of a primary monoblock in the root canal can be root canals completely obturated with mineral trioxide aggregate (MTA) as an apexification procedure. The $\mathrm{Ca}^{+}$and $\mathrm{OH}^{-}$ions released during hydration of MTA interact with tissue fluid and forms interfacial deposits similar to apatite; hence, MTA can be considered as a monoblock, though it does not bond to dentin and 

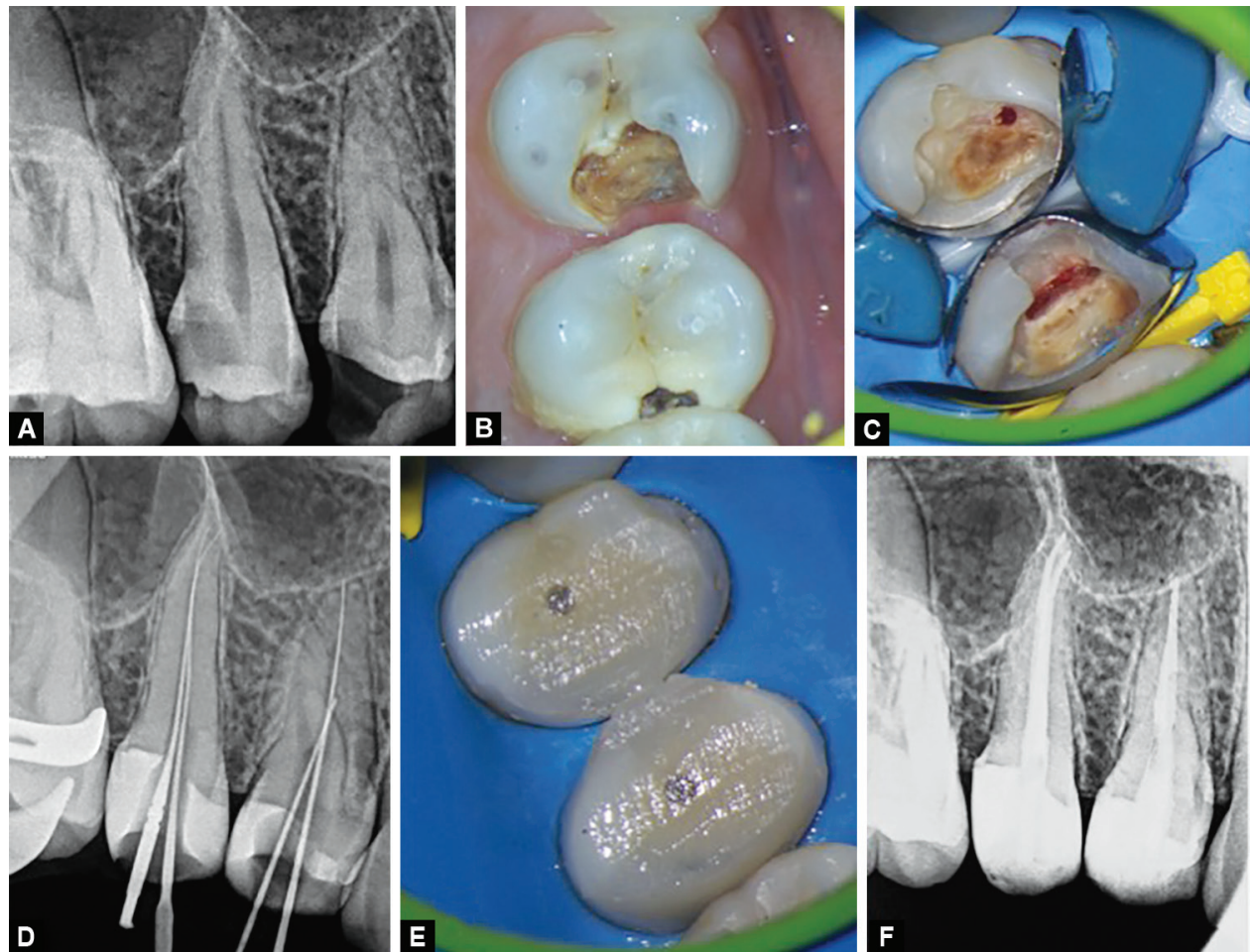

Figs 7A to F: Preendodontic buildup. Preoperative (A) Radiograph and (B) Clinical picture of upper premolars with extensive caries; (C) Complete caries removal reveals a weak tooth structure necessitating pre-endo buildup; (D) Teeth restored with a composite resin before initiating the endodontic procedure; ( $E$ and F) Post-endodontic restoration using fiber posts and composite resins to ensure a proper coronal seal threedimensionally. Courtesy: Dr Jojo Kottoor, MDS, Reader, Royal Dental College, Palakkad, Kerala, India


Figs 8A to G: Indirect onlay restoration. (A) Previous multiple attempts at restoration left the occlusal surface in shambles. Diagnosis: symptomatic irreversible pulpitis; (B and C) Single-visit endodontics was performed, tooth restored with the hybrid composite resin, and prepared for a ceramic onlay; (D) Dentin girth preserved with the intact buccal wall; (E to G) Photograph and radiograph after luting the onlay with the dual-cure resin cement 



Figs 9A to D: Minimal invasive endodontics in periodontally compromised teeth. Proximal caries (A) below the CEJ, (B) ultraconservative access cavity with all four canal orifices visible, (C) post-obturation and (D) post-endodontic restoration radiographs depicting completely restored but periodontally weak tooth. Courtesy: Dr Leeba Varghese, MDS, Kottayam, Kerala, India

also undergoes chemical shrinkage during hydration. ${ }^{75}$ Moreover, MOE of MTA ranges between 14 and $18 \mathrm{GPa}$, close to that of dentin, so that MTA should at least theoretically reinforce the roots.

A classic secondary monoblock that can act homogenously as a single unit, again theoretically, is the epoxy resin-embedded carbon/glass fiber posts luted with resin cement to root dentin. ${ }^{75}$ However, in vitro and in vivo studies could not validate this claim, even when the epoxy resin was replaced by the highly cross-linked methacrylate resin matrix free of the oxygen-inhibiting layer that will have a better bonding with the methacrylate-based resin cement. ${ }^{76}$ As of the present, this may be considered by far the most ideal monoblock.

\section{Clinical Tips for Effective Combination OF MIE AND EERP}

As stated in the beginning, it is always best to start planning with the end in mind. The effectiveness of the planning will be in finding the right balance between "not enough" and "too much."23 During diagnosis of endodontic lesions, the clinician should assess the tooth for restorability, periodontal status, and occlusal function. ${ }^{44}$

Pre-endodontic buildup is part of the MIE process and helps in assessing the remaining tooth structure and plan or replan the final restoration in the initial stages. In some clinical conditions, periodontally compromised teeth need to be retained for a short term or in elderly patients to avoid extensive treatment options. Restoration of such teeth is challenging for the clinician and decision should be based on minimal intervention till the survival of the tooth in question (Fig. 9).
A partial ferrule is better than no ferrule, if a full circumferential bevel is not possible. Even an adhesive post may not be effective if there is no ferrule (Fig. 10). At such times, it is better to do the crown lengthening procedure to obtain a shorter axial wall that when restored along with an adhesive post can help in making the restoration more predictable. The ill effects of intra-canal medicament (ICM) and irrigants on the root dentin and its adhesion to the fiber post ${ }^{77}$ can be overcome by the use of antioxidants and collagen cross-linkers. ${ }^{78,79}$

To summarize, the following clinical situations can be considered and acted upon accordingly. ${ }^{80-83}$ In younger patients with normal occlusion and periodontal conditions, three types of situations may be considered:

- When adequate 3D ferrule is present and the dentin girth is sufficient, no post is required both for bonded restorations and extra-coronal crowns.

- Short $(<1 \mathrm{~mm})$ ferrule with less than adequate remaining dentin thickness warrants use of post and indirect full coverage restoration. When dentin girth is minimal, preserving this remaining dentin thickness (RDT) becomes important; hence, the use of endocrowns that take retention from the internal walls of the access cavity is preferred. ${ }^{83}$

- If either one is present/absent, then a post is required if full coverage crowns are to be given. When bonded, reinforced direct composite restoration is done, no post is required.

As mentioned earlier, the decision may vary in many clinical conditions, such as geriatric patients, extreme occlusal conditions, periodontally weak teeth, high caries-risk patients, etc. An endodontist/general dentist performing both the endodontic 

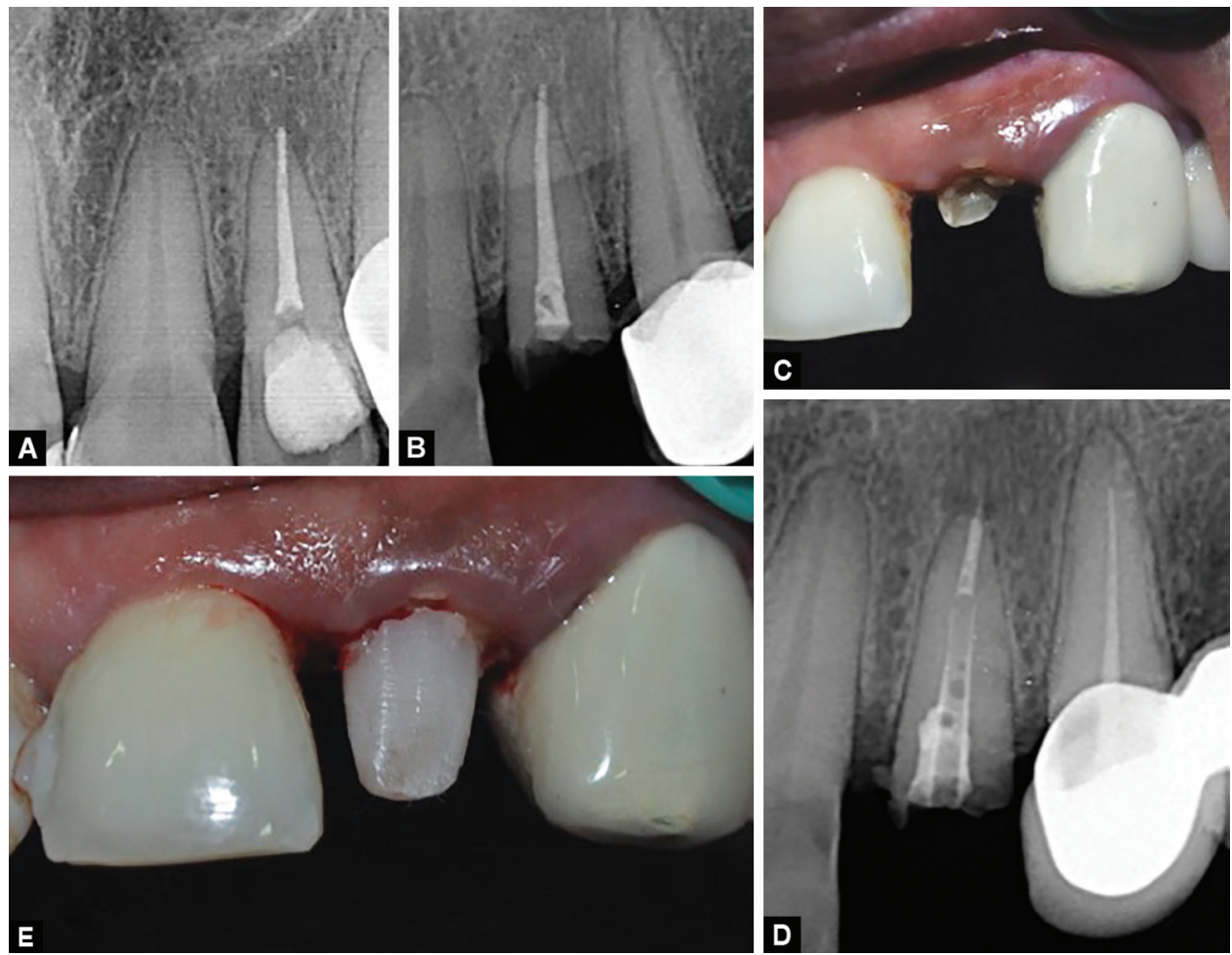

Figs 10A to E: Lack of (A) a ferrule resulting in fracture of (B and C) the coronal portion of the tooth due to delay in restoration; (D) Attempted fiber post with composite resin buildup resulted in (E) its fracture within 6 months of placement

procedure and the PER will be able to combine both the concepts of MID and EERP to the best interests of the patient.

\section{ConcLusion}

\section{Operation Successful; Patient Dead!}

This can be said of the endodontically successful but restoratively compromised ETT. The end result of the endodontic therapy should be the long-term sustainability of the ETT in the oral cavity. Shaping of root canals conforming to the canal anatomy, using more effective disinfection systems that do not require wider apical preparations, and hydraulics of bioceramic sealers that help in proper 3D seal unnecessitating larger taper to accommodate pluggers for the same promote biological success of MIE. Caseby-case decision on the PER to be placed keeping in mind the biomechanics of the ETT along with the condition in which it needs to survive; minimal coronal preparation, relying on the adhesive concepts of restorative materials and reducing the amount of natural tooth structure removed ensures improved survival rates over the years.

\section{ACKnowledgments}

The author wishes to thank Dr Jojo Kottoor, Dr Leeba Varghese, and $\mathrm{Dr}$ Anand $\mathrm{M}$. for their help with the figures for the article. The author acknowledges the help rendered by Dr S Vidhya and Dr Saravana Karthikeyan, SRM Dental College, in reviewing the article.

\section{References}

1. Tang $\mathbf{W}, \mathrm{Wu} Y$, et al. Identifying and Reducing Risks for Potential Fractures in Endodontically Treated Teeth. J Endod 2010;36(4): 609-617. DOI: 10.1016/j.joen.2009.12.002.
2. Salehrabi R, Rotstein I. Endodontic treatment outcomes in a large patient population in the USA: an epidemiological study. J Endod 2004 Dec;30(12):846-850. DOI: 10.1097/01.don.0000145031.04236. ca.

3. Gluskin $\mathrm{AH}$, Peters $\mathrm{Cl}$, et al. Minimally invasive endodontics: Challenging prevailing paradigms. Br Dent J 2014;216(6):347-353. DOI: 10.1038/sj.bdj.2014.201.

4. Kishen A. Mechanisms and risk factors for fracture predilection in endodontically treated teeth. Endod Topics 2006;13(1):57-83. DOI: 10.1111/j.1601-1546.2006.00201.x.

5. Touré B, Faye B, et al. Analysis of reasons for extraction of endodontically treated teeth: a prospective study. J Endod 2011;37(11):1512-1515. DOI: 10.1016/j.joen.2011.07.002.

6. PradeepKumar AR, Shemesh $\mathrm{H}$, et al. Diagnosis of Vertical Root Fractures in Restored Endodontically Treated Teeth: A Timedependent Retrospective Cohort Study. J Endod 2016;42(8): 1175-1180. DOI: 10.1016/j.joen.2016.04.012.

7. Chan $\mathrm{CP}$, Tseng $\mathrm{SC}$, et al. Vertical root fracture in non-endodontically treated teeth - a clinical report of 64 cases in Chinese patients. J Endod 1998;24:678-681. DOI: 10.1016/S0099-2399(98)80154-4.

8. Yeh CJ. Fatigue root fracture: a spontaneous root fracture in nonendodontically treated teeth. Br Dent J 1997;182:261-266. DOI: 10.1038/sj.bdj.4809363.

9. Versluis $\mathrm{A}$, Messer $\mathrm{HH}$, et al. Changes in compaction stress distributions in roots resulting from canal preparation. Int Endod J 2006;39:931-939. DOI: 10.1111/j.1365-2591.2006.01164.x.

10. Huynh N, Li FC, et al. Biomechanical Effects of Bonding Pericervical Dentin in Maxillary Premolars. J Endod 2018;44(4):659-664. DOI: 10.1016/j.joen.2018.01.002.

11. Dietschi D, Duc O, et al. Biomechanical considerations for the restoration of endodontically treated teeth: a systematic review of the literature, Part II (Evaluation of fatigue behavior, interfaces, and in vivo studies). Quintessence Int 2007;38:733-743.

12. González-López S, De Haro-Gasquet F, et al. Effect of Restorative Procedures and Occlusal Loading on Cuspal Deflection. Oper Dent 2006;31(1):33-38. DOI: 10.2341/04-165. 
13. Papa J, Cain C, et al. Moisture content of vital vs endodontically treated teeth. Dental Traumatol 1994;10(2):91-93. DOI: 10.1111/j.16009657.1994.tb00067.x.

14. Gale MS, Darvell BW. Dentine permeability and tracer tests. J Dent 1999:27:1-11. DOI: 10.1016/S0300-5712(98)00038-4.

15. Yan W, Montoya C, et al. Reduction in Fracture Resistance of the Root with Aging. J Endod 2017;43(9):1494-1498. DOI: 10.1016/ j.joen.2017.04.020

16. PradeepKumar AR, Shemesh $\mathrm{H}$, et al. Preexisting Dentinal Microcracks in Nonendodontically Treated Teeth: An Ex Vivo Micro-computed Tomographic Analysis. J Endod 2017;43(6):896-900. DOI: 10.1016/ j.joen.2017.01.026.

17. Russell A, Chandler NP, et al. The Butterfly Effect: An Investigation of Sectioned Roots. J Endod 2013;39:208-210. DOI: 10.1016/ j.joen.2012.09.016.

18. Russell A, He LH, et al. Investigation of Dentin Hardness in roots exhibiting the Butterfly Effect. J Endod 2014;40:842-844. DOI: 10.1016/j.joen.2013.11.005.

19. Arola D, Reprogel RK. Effects of aging on the mechanical behavior of human dentin. Biomaterials 2005;26:4051-4061. DOI: 10.1016/ j.biomaterials.2004.10.029.

20. Yan W, Montoya C, et al. Contribution of Root Canal Treatment to the Fracture Resistance of Dentin. J Endod 2019;45(2):189-193. DOI: 10.1016/j.joen.2018.10.004

21. Kishen A, Ramamurty $U$, et al. Experimental studies on the nature of property gradients in the human dentine. J Biomed Mater Res 2000;51:650-659. DOI: 10.1002/1097-4636(20000915)51:4<650::AIDJBM13>3.0.CO;2-H.

22. Gutmann JL. Minimally invasive dentistry (Endodontics). J Conserv Dent 2013;16:282-283. DOI: 10.4103/0972-0707.114342.

23. Nasseh AA, Trope $M$, et al. Minimally Invasive Endodontics: Finding the Right Balance Between "Too Much" and "Not Enough". Compendium Jan 2016;37(1).

24. Moore B, Verdelis K, et al. Impacts of contracted endodontic cavities on instrumentation efficacy and biomechanical responses in maxillary molars. J Endod 2016;42:1779-1783. DOI: 10.1016/ j.joen.2016.08.028.

25. Bürklein S, Schäfer E. Minimally invasive endodontics. Quintessence Int 2015;46(2):119-124.

26. Lacerda MF, Marceliano-Alves MF, et al. Cleaning and shaping oval canals with instrumentation systems: a correlative micro-computed tomographic and histologic study. J Endod 2017 Nov;43(11): 1878-1884. DOI: 10.1016/j.joen.2017.06.032.

27. Silva EJ, Vieira VT, et al. Cyclic and Torsional Fatigue Resistance of XP-endo Shaper and TRUShape Instruments. J Endod 2018 Jan;44(1):168-172. DOI: 10.1016/j.joen.2017.08.033.

28. Zuolo ML, Zaia AA, et al. Micro-CT assessment of the shaping ability of four root canal instrumentation systems in oval- shaped canals. Int Endod J 2018 May;51(5):564-571. DOI: 10.1111/iej.12810.

29. Soares CJ, Rodrigues $M$, et al. How biomechanics can affect the endodontic treated teeth and their restorative procedures? Braz Oral Res 2018;32(1):169-183. DOI: 10.1590/1807-3107bor-2018.vol32.0076.

30. Chatvanitkul C, Lertchirakarn V. Stress Distribution with Different Restorations in Teeth with Curved Roots: A Finite Element Analysis Study. J Endod 2010;36(1):115-118. DOI: 10.1016/j.joen.2009.09.026.

31. Bier CA, Shemesh $\mathrm{H}$, et al. The ability of different nickel-titanium rotary instruments to induce dentinal damage during canal preparation. J Endod 2009;35:236-238. DOI: 10.1016/j.joen.2008.10.021.

32. $\mathrm{M}$, Marending, Luder, $\mathrm{HU}$, et al. Effect of sodium hypochlorite on human root dentine - Mechanical, chemical and structural evaluation. International Endodontic Journal 40(10):786-793.

33. Zhang X, Xiao Z, et al. Biomineralization and Biomaterial Considerations in Dentin Remineralization. Journal of Operative Dentistry and Endodontics Jan-June 2016;1(1):7-12. DOI: 10.5005/ jp-journals-10047-0004.

34. Nakano F, Takahashi $\mathrm{H}$, et al. Reinforcement mechanism of dentin mechanical properties by intracanal medicaments. Dent Mater J 1999;18:304-313. DOI: 10.4012/dmj.18.304.
35. Soares CJ, Soares PV, et al. The Influence of Cavity Design and Glass Fiber Posts on Biomechanical Behavior of Endodontically Treated Premolars. J Endod 2008;34(8):1015-1019. DOI: 10.1016/ j.joen.2008.05.017.

36. Linn J, Messer HH. Effect of restorative procedures on the strength of endodontically treated molars. J Endod 1994;20:479-485. DOI: 10.1016/S0099-2399(06)80043-9.

37. Panitvisai $\mathrm{P}$, Messer HH. Cuspidal deflection in molars in relation to endodontic and restorative procedures. J Endod 1995;21:57-61. DOI: 10.1016/S0099-2399(06)81095-2.

38. Khera SC, Goel VK, et al. Parameters of MOD cavity preparations: A 3D FEM study. Oper Dent 1991;16:42-54.

39. Trope M, Langer I, et al. Resistance to fracture of restored endodontically treated premolars. Dent Traumatol 1986;2:35-38. DOI: 10.1111/j.1600-9657.1986.tb00120.x.

40. Randow K, Glanz PO. On cantilever loading of vital and non-vital teeth. An experimental clinical study. Acta Odontol Scand 1986;44:271-277. DOI: $10.3109 / 00016358609004733$.

41. Lang $\mathrm{H}$, Korkmaz $\mathrm{Y}$, et al. Impact of endodontic treatments on the rigidity of the root. J Dent Res 2006;85:364-368. DOI: $10.1177 / 154405910608500416$.

42. Corsentino G, Pedullà E, et al. Influence of Access Cavity Preparation and Remaining Tooth Substance on Fracture Strength of Endodontically Treated Teeth. J Endod 2018;44(9):1416-1421. DOI: 10.1016/j.joen.2018.05.012.

43. Clark D, Khademi J. Modern Molar Endodontic Access and Directed Dentin Conservation. Dent Clin North Am 2010;54(2):249-273. DOI: 10.1016/j.cden.2010.01.001.

44. Restoration of Endodontically Treated Teeth: The Endodontist's Perspective, Part 1. AAE: Endodontics Colleagues for Excellence, 1-6. www.aae.org.

45. Peroz I, Blankenstein F, et al. Restoring endodontically treated teeth with posts and cores-a review. Quintessence Int 2005;36(9):737-746.

46. Zarow $M$, Ramírez-Sebastià $A$, et al. A new classification system for the restoration of root filled teeth. Int Endod J 2018;51(3):318-334. DOI: $10.1111 /$ iej.12847.

47. Costa AK, Xavier TA, et al. Influence of Occlusal Contact Area on Cusp Deflection and Stress Distribution. J Contemp Dent Pract 2014;15(6):699-704.

48. Stankiewicz NR, Wilson PR. The ferrule effect: a literature review. Int Endod J 2002;35:575-581. DOI: 10.1046/j.1365-2591.2002.00557.x.

49. Juloski J, Radovic I, et al. Ferrule effect: A literature review. J Endod 2012;38(1):11-19. DOI: 10.1016/j.joen.2011.09.024.

50. Santos-Filho PCF, Veríssimo C, et al. Influence of ferrule, post system, and length on biomechanical behavior of endodontically treated anterior teeth. J Endod 2014;40(1):119-123. DOI: 10.1016/ j.joen.2013.09.034.

51. FedorowiczZ, Carter B, et al. Single crowns versus conventional fillings for the restoration of root filled teeth (Review). Cochrane Database Syst Rev 2012 May 16(5):CD009109. DOI: 10.1002/14651858.CD009109. pub2.

52. Kovarik RE, Breeding $L C$, et al. Fatigue life of three core materials under simulated chewing conditions. J Prosthet Dent 1992;68:584-590. DOI: 10.1016/0022-3913(92)90370-P.

53. Larson TD, Jensen JR. Microleakage of composite resin and amalgam core material under complete cast crowns. J Prosthet Dent 1980;44:40-44. DOI: 10.1016/0022-3913(80)90044-X.

54. Kanca J 3rd. Dental adhesion and the All-Bond system. J Esthet Dent 1991;3:129-132. DOI: 10.1111/j.1708-8240.1991.tb00984.x.

55. Donald $\mathrm{HL}$, Jeansonne BG, et al. Influence of dentinal adhesives and a prefabricated post on fracture resistance of silver amalgam cores. J Prosthet Dent 1997;77:17-22. DOI: 10.1016/S0022-3913(97)70201-4.

56. Lo CS, Millstein $\mathrm{PL}$, et al. In vitro shear strength of bonded amalgam cores with and without pins. J Prosthet Dent 1995;74:385-391. DOI: 10.1016/S0022-3913(05)80379-8.

57. Braem MJ, Lambrechts $P$, et al. In vitro fatigue behavior of restorative composites and glass ionomers. Dent Mater 1995;11:137-141. DOI: 10.1016/0109-5641(95)80049-2. 
58. Dionysopoulos $\mathrm{P}$, Kotsanos $\mathrm{N}$, et al. Secondary caries formation in vitro around fluoride-releasing restorations. Oper Dent 1994;19:183-188.

59. Wiegand A, Buchalla W, et al. Review on fluoride- releasing restorative materials - fluoride release and uptake characteristics, antibacterial activity and influence on caries formation. Dent Mater 2007;23: 343-362. DOI: 10.1016/j.dental.2006.01.022.

60. Luthira A, Srirekha A, et al. The reinforcement of polyethylene fiber and composite impregnated glass fiber on fracture resistance of endodontically treated teeth: An in vitro study. J Conserv Dent 2012;15:372-376. DOI: 10.4103/0972-0707.101914.

61. Sah SP, Datta K, etal. Evaluation of Fracture Resistance of Endodontically Treated Maxillary Premolars Restored with Three Different Core Materials: An In Vitro Study. Int J Oral Health Med Res 2018;5(6):31-37.

62. Dietschi D, Duc O, et al. Biomechanical considerations for the restoration of endodontically treated teeth: a systematic review of the literature, Part II (Evaluation of fatigue behavior, interfaces, and in vivo studies). Quintessence Int 2008;39(2):117-129.

63. Petersen RC. Discontinuous fiber-reinforced composites above critical length. J Dent Res 2005;84:365-370. DOI: $10.1177 / 154405910508400414$.

64. Xu HH, Quinn JB, et al. Effects of different whiskers on the reinforcement of dental resin composites. Dent Mater 2003;19: 359-367. DOI: 10.1016/S0109-5641(02)00078-7.

65. Schreiber CK. Polymethylmethacrylate reinforced with carbon fibres. Br Dent J 1971;130:29-30. DOI: 10.1038/sj.bdj.4802623.

66. Hamza TA, Rosensteil SF, et al. The effect of fiber reinforcement on the Fracture toughness and flexural strength of provisional restorative resins. J Prosthet Dent 2004;91:258-264. DOI: 10.1016/ j.prosdent.2004.01.005.

67. Eapen AM, Amirtharaj LV, et al. Fracture Resistance of Endodontically Treated Teeth Restored with 2 Different Fiber-reinforced Composite and 2 Conventional Composite Resin Core Buildup Materials: An In Vitro Study. J Endod 2017;43(9):1499-1504. DOI: 10.1016/ j.joen.2017.03.031.

68. Schliebe LRO, Braga SSL, et al. The new generation of conventional and bulk-fill composites do not reduce the shrinkage stress in endodontically-treated molars. Am J Dent 2016 Dec;29(6):333-338.

69. Reeh ES, Douglas WH, et al. Stiffness of endodontically treated teeth related to restoration technique. J Dent Res 1989;68:1540-1544. DOI: $10.1177 / 00220345890680111401$

70. Cheung W. A review of the management of endodontically treated teeth: Post, core and the final restoration. J Am Dent Assoc 2005 May;136:611-619. DOI: 10.14219/jada.archive.2005.0232.

71. Vinola MJS, Balasubramanian S, et al. "ENDOCROWN"—An Effective Viable Esthetic Option for Expurgated Endodontically treated Teeth:
Two Case Reports. J Oper Dent Endod 2017;2(2):97-102. DOI: 10.5005/ jp-journals-10047-0046.

72. Zhou L, Wang Q. Comparison of fracture resistance between cast posts and fiber posts: a meta-analysis of literature. J Endod 2013;39(1):11-15. DOI: 10.1016/j.joen.2012.09.026.

73. Ambica K, Mahendran K, et al. Comparative evaluation of fracture resistance under static and fatigue loading of endodontically treated teeth restored with carbon fiber posts, glass fiber posts, and an experimental dentin post system: An in vitro study. J Endod 2013;39(1):96-100. DOI: 10.1016/j.joen.2012.07.003.

74. Kathuria A, Kavitha M. Ex vivo fracture resistance of endodontically treated maxillary central incisors restored with fiber-reinforced composite posts and experimental dentin posts. J Conserv Dent 2011;14:401-405. DOI: 10.4103/0972-0707.87211.

75. Tay FR, Pashley DH. Monoblocks in Root Canals: A Hypothetical or a Tangible Goal. J Endod 2007;33(4):391-398. DOI: 10.1016/ j.joen.2006.10.009.

76. Ferrari M, Goracci C, et al. An investigation of the inter-facial strengths of methacrylate resin-based glass fiber post-core build-ups by their components. J Adhes Dent 2006 Aug;8(4):239-245.

77. Schwartz RS. Adhesive Dentistry and Endodontics. Part 2: Bonding in root canal system - the promise and the problems: A review. J Endod 2006;32:1125-1134. DOI: 10.1016/j.joen.2006.08.003.

78. Manimaran VS, Srinivasulu S, et al. Application of a proanthocyanidin agent to improve the bond strength of root dentin treated with sodium hypochlorite. J Conserv Dent 2011;14:306-308. DOI: 10.4103/0972-0707.85822.

79. Lai SC, Mak YF, et al. Reversal of compromised bonding to oxidized etched dentin. J Dent Res 2001;80:1919-1924. DOI: 10.1177/00220345010800101101.

80. Salameh Z, Sorrentino R, et al. Fracture Resistance and Failure Patterns of Endodontically Treated Mandibular Molars Restored Using Resin Composite With or Without Translucent Glass Fiber Posts. J Endod 2006;32(8):752-755. DOI: 10.1016/j.joen.2006.02.002.

81. Al-Omiri MK, Mahmoud AA, et al. Fracture Resistance of Teeth Restored with Post-retained Restorations: An Overview. J Endod 2010;36:1439-1449. DOI: 10.1016/j.joen.2010.06.005.

82. Dietschi $D$, Bouillaguet $S$, et al. Restoration of endodontically treated teeth. Berman \& Hargreaves' Cohen's Pathways of the Pulp, 10th ed., Elsevier; 2010. pp. 789-793.

83. Mohammadi N, Kahnamoii MA, et al. Effect of Fiber Post and Cusp Coverage on Fracture Resistance of Endodontically Treated Maxillary Premolars Directly Restored with Composite Resin. J Endod 2009;35(10):1428-1432. DOI: 10.1016/j.joen.2009. 07.010 . 